\title{
PELATIHAN AUDIT INTERNAL PENGGUNAAN DANA BOS UNTUK KEPALA SEKOLAH, BENDAHARA, ADMINISTRASI SMP KOTA TANGERANG SELATAN GUGUS 03
}

\author{
Krida Puji Rahayu, Ratna Wati, Yusep Prihanto, Tri Wartono, Yusni Nuryani \\ Universitas Pamulang \\ Email:dosen01666@unpam.ac.id
}

\begin{abstract}
At this PKM by taking the research object is the principal, treasurer, administration of SMP Kota Tangerang Selatan cluster 03. The problem is derived from lack of knowledge and the school principal, treasurer related to his management function especially related to internal audit. An extension Program that will be provided by experts in the field of Audit is expected to provide audit knowledge to the supervisors. The PKM Program is expected to be an opportunity for the supervisors to discuss with the resource related to managerial functions, especially internal audit in junior high school. Supervisors are the headmaster of school management, improving the teacher's performance and education in carrying out the task. Understanding the concept of program development, powering technology in improving the quality of education. One of the crucial competencies is the managerial function where the school supervisor should know what the function and responsibilities are. School supervisors have a duty to examine financial statements which are a form of their managerial functions. In the implementation of the supervisory role as well as an auditor role which includes analysing, consulting, assessing organizational members for effectiveness in their mandate, informing the actions that have been reviewed, and giving Recommendations. The scope of internal audit includes the assessment and evaluation of the adequacy and effectiveness of internal control systems owned by the organization and the quality of implementation of the responsibilities provided.
\end{abstract}

Keywords: Internal audit training, school supervisor, Dana BOS

\begin{abstract}
Abstrak
Pada PKM ini dengan mengambil objek penelitian yaitu Kepala Sekolah, Bendahara, Administrasi SMP Kota Tangerang Selatan Gugus 03. Masalah yang diambil berasal dari kurang pengetahuan dan pahamnya kepala sekolah, bendahara terkait fungsi manajerialnya khususnya terkait audit internal. Program penyuluhan yang akan diberikan oleh narasumber yang ahli di bidang Audit diharapkan mampu memberikan pengetahuan audit kepada para pengawas. Program PKM ini diharapkan menjadi kesempatan bagi para pengawas berdiskusi dengan narasumber terkait fungsi manajerial khususnya audit internal di SMP. Pengawas merupakan pembina kepala sekolah dalam pengelolaan sekolah, meningkatkan kinerja guru dan tenaga
\end{abstract}


kependidikan dalam melaksanakan tugas pokoknya. Memahami konsep pengembangan program, mendayagunakan teknologi dalam meningkatkan mutu pendidikan. Salah satu kompetensi yang krusial adalah fungsi manajerial dimana pengawas sekolah harus tahu akan apa yang menjadi fungsi dan tanggung jawabnya. Pengawas sekolah memiliki tugas untuk memeriksa laporan keuangan yang merupakan wujud fungsi manajerialnya. Pada pelaksanaannya peran pengawas seperti halnya peran auditor yang meliputi penganalisaan, konsultasi, menilai anggota-anggota organisasi atas efektivitas dalam amanat mereka, menginformasikan tindakan-tindakan yang telah direview, dan memberi rekomendasi. Ruang lingkup audit internal meliputi pemeriksaan dan evaluasi kecukupan dan keefektifan sistem pengendalian internal yang dimiliki organisasi dan kualitas pelaksanaan tanggung jawab yang diberikan.

Kata Kunci: Pelatihan audit internal, pengawas sekolah, Dana BOS

\section{A. PENDAHULUAN}

Salah satu standar yang dinilai paling langsung berkaitan dengan mutu lulusan adalah standar pendidik dan tenaga kependidikan. Untuk dapat mencapai mutu pendidikan yang diinginkan, tenaga pendidik atau guru dituntut memiliki kualifikasi akademik dan kompetensi sebagai agen pembelajaran. Kualifikasi akademik ditunjukkan dengan ijazah dan atau sertifikat keahlian yang relevan dengan kualifikasi minimal sarjana (S1) pada setiap jenis dan jenjang pendidikan. Sedangkan kompetensi tenaga pendidik mencakup kompetensi pribadi, pedagogik, sosial dan kompetensi profesional.

Selain tenaga pendidik, peningkatan mutu pendidikan juga menuntut adanya tenaga kependidikan yang memadai. Tenaga kependidikan yang ada dan memerlukan pembinaan dan pengembangannya pada saat ini terdiri atas: (1) tenaga kepala sekolah, (2) tenaga pengawas, (3) tenaga laboran/teknisi, (4) tenaga perpustakaan dan (5) tenaga tata usaha. Tenaga kependidikan di atas terutama tenaga laboran, tenaga perpustakaan dan tata usaha kurang mendapat perhatian dalam hal pembinaan dan pengembangannya dibandingkan dengan tenaga pendidik. Sedangkan tenaga kepala sekolah dan tenaga pengawas sudah ada dan sudah berfungsi di setiap jenis dan jenjang pendidikan, walaupun pembinaan dan pengembangan secara akademik masih belum terpola dan berkesinambungan.

Tenaga pengawas TK/SD, SMP, SMA dan SMK merupakan tenaga kependidikan yang peranannya sangat penting dalam membina kemampuan profesional tenaga pendidik dan kepala sekolah dalam meningkatkan kinerja sekolah. Pengawas hendaknya berperan sebagai konsultan pendidikan yang senantiasa menjadi pendamping bagi guru dan kepala sekolah dalam meningkatkan mutu pendidikan. Lebih dari itu kehadiran pengawas harus menjadi agen dan pelopor dalam inovasi pendidikan di sekolah binaannya. Kinerja pengawas salah satunya harus dilihat dari kemajuan-kemajuan yang dicapai oleh sekolah binaannya. Dalam konteks itu maka mutu pendidikan di sekolah yang dibinanya akan banyak tergantung kepada kemampuan profesional tenaga pengawas.

Pengawas merupakan pembina kepala sekolah dalam pengelolaan sekolah, meningkatkan kinerja guru dan tenaga kependidikan dalam melaksanakan tugas pokoknya. Memahami konsep pengembangan program, mendayagunakan teknologi dalam meningkatkan mutu pendidikan. Pengawas sebagai salah satu pilar penjamin mutu pembelajaran dan mutu pendidikan dipersyaratkan memiliki kompetensi kepribadian, supervisi manajerial, akademik, evaluasi pendidikan, penelitian dan pengembangan serta 
kompetensi sosial. Dengan kompetensi itu dapat menunaikan kewajiban menumbuhkan motivasi diri serta menguasai prinsip-prinsip supervisi sehingga memiliki tingkat kesiapan melaksanakan tugas pemantauan, supervisi, penilaian, pembinaan, pelaporan dan tindak lanjut hasil pengawasan sebagai insan pembina sekolah.

Pada pelaksanaannya peran pengawas seperti halnya peran auditor yang meliputi penganalisaan, konsultasi, menilai anggota-anggota organisasi atas efektivitas dalam melaksanakan tanggung jawab mereka, menginformasikan tindakan-tindakan yang telah direview dan memberikan rekomendasi (Wuryan Andayani, 2011:3). Ruang lingkup audit internal meliputi pemeriksaan dan evaluasi kecukupan dan keefektifan sistem pengendalian internal yang dimiliki organisasi dan kualitas pelaksanaan tanggung jawab yang diberikan.

Program audit adalah tindakan-tindakan atau langkah-langkah yang terinci yang akan dilaksanakan dalam pemeriksaan. Selain sebagai petunjuk mengenai langkah-langkah yang harus dilaksanakan, program pemeriksaan juga merupakan alat kendali audit intern. Program disusun dengan manfaat-manfaat sebagai berikut (Tugiman, 2006: 75):

1. Menetapkan tanggung jawab untuk setiap prosedur pemeriksaan

2. Pembagian kerja yang rapi sehingga seluruh unit terperiksa secara menyeluruh

3. Menghasilkan pelaksanaan pemeriksaan yang tepat dan hemat waktu

4. Menekankan prosedur yang paling penting untuk setiap pemeriksaan

5. Berfungsi sebagai pedoman pemeriksaan yang dapat digunakan secara berkesinambungan

6. Mempermudah penilaian manajemen terhadap pelaksanaan pemeriksaan

7. Memastikan dipatuhinya norma-norma pemeriksaan dan prinsip-prinsip akuntansi yang diterima umum

8. Memastikan bahwa pemeriksa intern memperhatikan alasan-alasan dilaksanakannya berbagai prosedur.

Audit internal harus terus-menerus meninjau atau melakukan tindak lanjut untuk memastikan bahwa terhadap temuan-temuan audit yang dilaporkan telah dilakukan tidakan yang tepat dan tidak berulang untuk hal yang sama. audit intern harus memastikan apakah suatu tindakan korektif terhadap berbagai temuan yang dilaporkan. Dalam hal ini manajemen bertanggung jawab untuk menentukan tidakan yang perlu untuk dilakukan sebagai tanggapan terhadap temuan-temuan audit yang dilaporkan. Sedangkan Kontrol Intern bertanggung jawab untuk memperkirakan suatu tindakan yang diperlukan manajemen, agar berbagai hal yang dilaporkan sebagai temuan audit tersebut dapat diselesaikan dan ditanggulangi secara tepat waktu. Dalam menentukan luas dari tindak lanjut, audit intern harus mempertimbangkan berbagai prosedur dari hal-hal yang berkaitan dengan tindak lanjut, yang dilaksanakan oleh pihak lain dalam organisasi.

Pada program kegiatan masyarakat ini dengan mengambil objek penelitian yaitu Kepala Sekolah, Bendahara, Administrasi SMP Kota Tangerang Selatan Gugus 03. Masalah yang diambil pada intinya berasal dari latar belakang pengawas yang tidak semuanya paham akan fungsi manjaerialnya khususnya terkait audit internal. Program penyuluhan yang akan diberikan oleh narasumber yang ahli di bidang Audit diharapkan mampu memberikan pengetahuan audit kepada para pengawas. Program PKM ini diharapkan menjadi kesempatan bagi para pengawas berdiskusi dengan narasumber terkait fungsi manajerial khususnya audit internal di SMP SMP Se-Kota Tangerang Selatan.

Berdasarkan hasil observasi pendahuluan yaitu wawancara dari beberapa pengawas SMP Kota Tangerang Selatan, sebagian besar menyatakan jika mereka kesulitan untuk melakukan supervisi terkait analisa laporan keuangan lebih tepatnya bagaimana mereka melaksanakan kegiatan audit internal terhadap laporan keuangan dana BOS. Kurangnya pengetahuan ini didasarkan dari latar belakang para pengawas yang berbeda fungsi pokoknya dengan fungsi supervisi terutama fungsi manajerial. Permasalahan pada analisa laporan 
keuangan menjadi titik lemah yang tentunya akan meraguka hasil kerja pengawas. Padahal peran audit dalam laporan analisa keuangan dana BOS merupakan peran utama seorang pengawas.

\section{B. METODE PELAKSANAAN KEGIATAN}

Tujuan pelaksanaan dari kegiatan PKM ini adalah meaksimalkan kinerja pengawas SMP Se-Kota Tangerang Selatan. Fokusnya yaitu pada fungsi manajerial pengawas sekolah yaitu meliputi : (a) manajemen kurikulum dan pembelajaran, (b) manajemen kesiswaan, (c) manajemen sarana dan prasarana, (d) manajemen ketenagaan, (e) manajemen keuangan, (f) manajemen hubungan sekolah dengan masyarakat, (g) manajemen layanan khusus. Fokus utamanya yaitu terkait dengan manajemen keuangan pada analisa laporan keuangan dana BOS dimana para pengawas memposisikan dirinya sebagai seorang auditor dengan tujuan agar dapat mewujudkan keberhasilan dalam meningkatkan mutu pendidikan.

Metode kegiatan yang digunakan adalah bekerjasama dengan para pengawas SMP SeKota Tangerang Selatan dan mencari pemasalahan yang dialami mereka pada waktu menjalankan tugas dan fungsinya sebagai supervisi akademik dan supervisi manajerial sehingga dapat memberikan solusi yang tepat dalam memberikan penyuluhan kepada mereka dalam kaitannya peran supervisi sebagai auditor internal di lingkungan SMP Se-Kota Tangerang Selatan. Setelah di analisis maka kami memberikan penyuluhan dalam bentuk materi dan praktek dalam mengembangkan kinerja pada peran supervisor manajerial pada manajemen keuangan terkait pengauditan internal laporan keuangan dana BOS.

Berikut ini adalah tahapan pelatihan yang dilakukan:

1. Tahap persiapan, Tahap persiapan yang dilakukan meliputi:

a. Survey awal,

b. Pemantapan dan penentuan lokasi dan sasaran. Setelah survey maka ditentukan lokasi pelaksanaan dan sasaran peserta kegiatan.

2. Tahap Pelaksanaan Pengabdian Kepada Masyarakat

Tahap ini akan diberikan penjelasan mengenai apa itu Audit Internal dana BOS. Sesi ini menitik beratkan pada pemberian penjelasan mengenai bagaimana penerapan audit internal.

3. Tahap Pelatihan

Untuk melaksanakan kegiatan tersebut digunakan beberapa metode pelatihan yaitu:

a. Metode ceramah

b. Metode tanya jawab

Metode simulasi

Program Pengabdian Kepada Masyarakat yang akan kami lakukan di SMP N 04 Tangerang Selatan dengan objek penelitian yaitu Kepala Sekolah, Bendahara, Administrasi SMP Kota Tangerang Selatan Gugus 03 adalah.

1. Memberikan pengetahuan terkait fungsi manajerial dalam manajemen keuangan merujuk pada Standar Pembiayaan. Fungsi audit internal dalam memeriksa, menganalisa, dan mengevaluasi, dan efektivitas sistem pengendalian internal organisasi dan kualitas kinerja dalam pelaporan keuangan dana BOS.

2. Memberikan pengetahuan dalam menelaah reliabilitas dan integritas informasi keuangan dan operasi serta perangkat yang digunakan untuk mengidentifikasi, mengukur, mengklarifikasi, dan melaporkan informasi semacam itu.

3. Memberikan pengetahuan dalam menilai keekonomian dan efisiensi sumber daya yang dipergunakan khususnya penggunaan dana BOS untuk keperluan pendidikan siswa SMP Se-Kota Tangerang Selatan. 
4. Memberikan pengetahuan dalam menelaah sistem yang ditetapkan untuk memastikan ketaatan terhadap kebijakan, perencanaan, prosedur, hukum, dan peraturan yang dapat berpengaruh signifikan terhadap operasi dan laporan keuangan dana BOS, serta menentukan apakah organisasi telah mematuhinya.

\section{HASIL DAN PEMBAHASAN}

\section{Tahap Persiapan}

Sebelum melaksanakan Pengabdian Kepada Masyarakat kami selaku Dosen Universitas Pamulang melakukan pra-survey kepada beberapa sekolah di wilayah Tangerang selatan. Berdasarkan data dan informasi yang kami dapatkan bahwa penerapan audit internal dan BOS masih belum terlaksana dengan baik.

Hal ini menuntut para stakeholder sekolah untuk memahami mengenai pentingnya audit internal laporan keuangan pengunaan dana BOS. Oleh karena itu, kami Dosen Universitas Pamulang melakukan pertemuan dengan SMP N 04 Tangerang Selatan untuk memberikan solusi terhadap permasalahan mengenai pelatihan audit internal penggunaan dana BOS untuk Kepala Sekolah, Bendahara, Administrasi SMP Kota Tangerang Selatan Gugus 03.

Setelah itu, TIM PKM yang terdiri dari lima orang Dosen UNPAM melakukan Forum Group Discussion (FGD) untuk mempersiapkan pelaksanaan Pengabdian Kepada Masyarakat (PKM) untuk tanggal di SMP N 04 Tangerang Selatan.

\section{Tahap Pelaksanaan Pengabdian Kepada Masyarakat}

Pelaksanaan Pengabdian Kepada Masyarakat di Lembaga Pemberdayaan Masyarakat pada tanggal 9 - 11 Desember 2019. Kegiatan dilaksanakan di Aula SMP N 04 Tangerang Selatan. Kegiatan ini terlaksana atas kerjasama Universitas Pamulang dengan SMP N 04 Tangerang Selatan. dengan tema "Pelatihan Audit Internal Penggunaan Dana BOS untuk Kepala Sekolah, Bendahara, Administrasi SMP Kota Tangerang Selatan Gugus 03". Kegiatan ini di ketuai oleh Ibu Krida Puji Rahayu dengan narasumber Bapak Yusep Prihanto dan Bapak Tri Wartono serta dibantu dosen UNPAM lainnya yaitu Dra. Ratnawati, M.M., dan Yusni Nuryani, S.E., M.M. Kegiatan PKM ini dihadiri kebanyakan dari kalangan Kepala Sekolah, Bendahara, Administrasi SMP Kota Tangerang Selatan Gugus 03.

\section{Tahap Pelatihan}

Untuk melaksanakan kegiatan tersebut digunakan beberapa metode pelatihan yaitu:

a. Metode ceramah

Metode yang digunakan dalam pelatihan SDM dimulai dengan memberikan ceramah atau presentasi dengan tema "Pelatihan Audit Internal Penggunaan Dana BOS untuk Kepala Sekolah, Bendahara, Administrasi SMP Kota Tangerang Selatan Gugus 03”, dengan narasumber Bapak Yusep Prihanto yang dibantu oleh Ibu Ratnawati sebagai moderator.

b. Metode tanya jawab

Setelah sesi ceramah sudah selesai, maka dilanjutkan dengan sesi tanya jawab. Hasilnya, peserta sangat antusias untuk menanyakan bagaimana cara Audit internal dana BOS bisa berjalan dengan baik. Peserta yang bertanya kami berikan cendremata dari Universitas Pamulang dan sumbangsih dari dosen-dosen UNPAM.

c. Metode simulasi

Pelatihan ini juga diberikan metode simulasi, sehingga peserta langsung dapat mempraktekan apa yang sudah disampaikan. Apabila ada kendala maka langsung 
dibantu pada saat pelaksanaan PKM. Simulasi penting dilakukan untuk mengetahui seberapa besar tingkat pengetahuan dan ilmu yang diserap pada saat pelatihan.

\section{KESIMPULAN DAN SARAN}

\section{Simpulan}

Pelaksanaan kegiatan Pengabdian Kepada Masyarakat oleh Lembaga Penelitian dan Pengabdian Masyarakat (LPPM) Universitas Pamulang yang dilakukan oleh dosen-dosen program studi Manajemen telah berjalan dengan lancar dan mendapat sambutan hangat dari tempat pelaksanaan kegiatan ini yaitu Kepala SMP N 04 Tangerang Selatan. Harapan kami dengan pengabdian ini dapat menambah ilmu yang bermanfaat dalam hal audit internal dana BOS.

Dalam laporan kegiatan ini mungkin banyak kekurangan yang ada, untuk itu kami berharap masukan dan kritikan dalam rangka perbaikan untuk kegiatan-kegiatan pengabdian masyarakat di masa yang akan datang. Semoga kegiatan pengabdian masyarakat ini dapat bermanfaat bagi masyarakat sekitar lingkungan Universitas Pamulang dan lainnya.

Akhirnya, kami mengucapkan terima kasih kepada seluruh pihak yang telah mendukung kegiatan yang kami laksanakan dan kami mohon maaf apabila dalam laporan ini banyak ditemukan kekurangan.

\section{Saran}

Berdasarkan hasil kegiatan Pengabdian Kepada Masyarakat, maka kami dari Tim Dosen Universitas Pamulang memberikan saran diantaranya sebagai berikut:

1. Untuk pihak sekolah dan seluruh jajaran stakeholder untuk lebih mengedepankan prinsipprinsip akuntabilitas dalam proses laporan keuangan yang nantinya akan mempermudah proses audit dan agar proses audit dijalankan sesuai prinsip prinsip audit yang telah dijelaskan dalam materi pelatihan.

2. Adanya kontribusi dari pihak universitas untuk bisa memberikan fasilitas dalam pelayanan kepada masyarakat dalam bentuk sarana dan prasarana.

\section{Ucapan Terima Kasih}

Rasa syukur dan suka cita kamu haturkan kepada segenap pihak yang telah mensukseskan kegiatan PKM dengan judul "Pelatihan Audit Internal Penggunaan Dana BOS untuk Kepala Sekolah, Bendahara, Administrasi SMP Kota Tangerang Selatan Gugus 03" kepada:

1. Rektor Dr. H. Dayat Hidayat, M.M, Rektor Universitas Pamulang Tangerang Selatan Banten.

2. Dr. Ali Maddinsyah, S.E., M.M., selaku Ketua LPPM Universitas Pamulang Tangerang Selatan - Banten.

3. Dr. Kasmad, S.E., M.,M., selaku Ketua Program Studi Manajemen Universitas Pamulang Tangerang Selatan - Banten.

4. Dr. Udin Ahidin, S.E., M.M., C.M.A, Selaku Wakil Program Studi Manajemen Universitas Pamulang Tangerang Selatan - Banten.

5. Drs. Waluyo Jati, M.M., Selaku Sekretaris Program Studi Manajemen Universitas Pamulang Tangerang Selatan - Banten.

6. Drs. Yantho, M.M., selaku Kepala SMP N 04 Kota Tangerang Selatan - Banten.

7. Kepala Sekolah, Bendahara, dan Administrasi SMP Se-Kota Tangerang Selatan Gugus 02 - Banten. 
8. Mahasiswa Universitas Pamulang yang juga ikut berkontribusi terhadap kelancaran kegiatan PKM.

\section{DAFTAR PUSTAKA}

Agoes, Sukrisno. (2012). Auditing Petunjuk Praktis Pemeriksaan Akuntan Oleh Akuntan Publik, Jilid 1, Edisi Keempat. Jakarta: Salemba Empat.

Amrizal. (2004). Pencegahan dan Pendeteksian Kecurangan oleh Internal Auditor. Diklat BPKP.

Andayani, Wuryan. (2008). Audit Internal (Edisi 1). Yogyakarta: BPFE.

Arens, A. A., Elder R. J., \& Beasley, M. S. (2008). “Auditing dan Jasa Assurance Pendekatan Terintegrasi”. Jakarta: Erlangga.

Bastian, Indra. (2013). Sistem Akuntansi Sektor Publik, edisi 3. Jakarta: Salemba Empat.

Cahyo, M. N., \& Sulhani. (2017). “Analisis Empiris Pengaruh Karakteristik Komite Audit, Karakteristik Internal Audit, Whistleblowing System, Pengungkapan Kecurangan Terhadap Reaksi Pasar”. Jurnal Dinamika Akuntansi dan Bisnis, Vol.4 No. 2.

Kemendiknas. (2007). Permendiknas No. 13 Tahun 2007 tentang Standar Kompetensi Kepala Sekolah. Jakarta. Pusat Pengembangan Tenaga Kependidikan.

Keputusan Menteri Negara Pendayagunaan Aparatur Negara Nomor 118/1996 tentang Jabatan Fungsional Pengawas dan Angka Kreditnya. Jakarta: Dirjen Dikdasmen.

Krina, Loina Lalolo. P. (2003). Indikator dan Alat ukur Prinsip Akuntabilitas, Transparansi dan Partisipasi. Jakarta: Badan Perencanaan Pembangunan Nasional.

Mardiasmo. (2009). Akuntansi Sektor Publik. Yogyakarta: Andi.

Mulyono. (2010). Manajemen Berbasis Sekolah. Yogyakarta: Ar-Ruzz Media.

Sawyer, B. (2012). Sawyer's Internal Audit, Buku 2. Jakarta: Salemba Empat.

Suparjio. (2000). Pengelolaan Keuangan Di Sekolah Dasar Se-Ranting Dinas P dan K Kecamatan Piyungan Kabupaten Bantul Yogyakarta”. Abstrak. Skripsi. FIP-UNY.

Peraturan Mendiknas Nomor 69 Tahun 2009, standar biaya operasi nonpersonalia.

Peraturan Pemerintah No 19 tahun 2005 tentang Standar Pendidikan Nasional.

Peraturan Pemerintah Nomor 48 tahun 2008 tentang pendanaan pendidikan, biaya non personalia.

Ristya, Dwi Anggraini. (2013). Transparansi, Partisipasi, dan Akuntabilitas Pengelolaan Anggaran Dana BOS Dalam Program RKAS di SDN Pacarkeling VIII Surabaya. Jurnal Kebijakan dan Manajemen Publik, Vol. 1 No. 2.

Sahertian, Piet, A. (2000). Konsep Dasar dan Teknik Supervisi akademik. Jakarta: PT. Rineka Cipta.

Tugiman, Hiro. (2011). Pandangan Baru Internal Auditing. Yogyakarta: Kanisius. 